\title{
Respon Mahasiswa Terhadap Perkuliahan Berbasis Kearifan lokal Pada Mata Kuliah Kajian Fisika Sekolah Menengah
}

\author{
${ }^{1}$ Hikmawati, ${ }^{2}$ I Wayan Suastra \\ ${ }^{1}$ Prodi Pendidikan Fisika, FKIP, Universitas Mataram, Jln. Majapahit No. 62, Mataram, NTB, \\ Indonesia, 83125 \\ ${ }^{2}$ Pendidikan IPA, FMIPA, Universitas Pendidikan Ganesha, Jln. Udayana No. 11, Singaraja, \\ Bali, Indonesia, 81116 \\ Email Korespondensi: hikmawati@unram.ac.id
}

\begin{tabular}{|c|c|}
\hline Article Info & bstract \\
\hline $\begin{array}{l}\text { Article History } \\
\text { Received: } 28 \text { November } 2021 \\
\text { Revised: } 18 \text { December } 2021 \\
\text { Published: } 30 \text { December } 2021\end{array}$ & \multirow{2}{*}{$\begin{array}{l}\text { Student Responses to Lectures Based on Local Wisdom in High School } \\
\text { Physics Studies Course. This study aims to describe student responses to local } \\
\text { wisdom-based lectures in the High School Physics Studies course. This type of } \\
\text { research is descriptive research. The research subjects were } 27 \text { th semester } \\
\text { students at one of the universities in the city of Mataram. The research was } \\
\text { carried out from } 18 \text { August } 2021 \text { to } 27 \text { October } 2021 \text { with a total of } 10 \\
\text { meetings. Lectures are conducted online through the Learning Management } \\
\text { System (LMS). The research data was obtained by providing response } \\
\text { questionnaires to students in the form of a google form at the end of the lecture. } \\
\text { Student responses are said to be positive towards local wisdom-based lectures } \\
\text { in terms of } 4 \text { aspects, namely happy, new, enthusiastic, and interested, which is } \\
\text { at least } 75 \% \text { Each aspect has } 5 \text { components that are assessed, namely lecture } \\
\text { material, LMS discussion forums, student learning methods, lecturers' teaching } \\
\text { methods, and assessment in the form of assignments. The results showed that } \\
96 \% \text { of students said they were happy, } 78 \% \text { of students said they were new, } \\
89 \% \text { of students said they were enthusiastic, and } 91 \% \text { of students said they } \\
\text { were interested in lectures based on local wisdom. Thus, students expressed a } \\
\text { positive response to local wisdom-based lectures on each component of the } \\
\text { assessment. }\end{array}$} \\
\hline $\begin{array}{l}\text { Keywords } \\
\text { response; local wisdom; LMS; } \\
\text { Physics }\end{array}$ & \\
\hline Info & $\mathbf{k}$ \\
\hline $\begin{array}{l}\text { Sejarah Artikel } \\
\text { Diterima: } 28 \text { November } 2021 \\
\text { Direvisi: } 18 \text { Desember } 2021 \\
\text { Dipublikasi: } 30 \text { Desember } 2021\end{array}$ & \multirow{2}{*}{$\begin{array}{l}\text { Penelitian ini bertujuan untuk mendeskripsikan respon mahasiswa terhadap } \\
\text { perkuliahan berbasis kearifan lokal pada mata kuliah Kajian Fisika Sekolah } \\
\text { Mengah. Jenis penelitian ini adalah penelitian deskriptif. Subjek penelitian } \\
\text { berjumlah } 27 \text { orang mahasiswa semester } 5 \text { pada salah satu perguruan tinggi di } \\
\text { kota Mataram. Penelitian dilaksanakan sejak tanggal } 18 \text { Agustus } 2021 \text { hingga } \\
27 \text { Oktober } 2021 \text { dengan jumlah pertemuan sebanyak } 10 \text { kali. Perkuliahan } \\
\text { dilakukan secara online melalui Learning Management System (LMS). Data } \\
\text { penelitian diperoleh dengan memberikan angket respon kepada mahasiswa } \\
\text { dalam bentuk google form di akhir perkuliahan. Respon mahasiswa dikatakan } \\
\text { positif terhadap perkuliahan berbasis kearifan lokal ditinjau dari } 4 \text { aspek yaitu } \\
\text { senang, baru, antusias, dan tertarik adalah minimal sebesar } 75 \% \text {. Setiap aspek } \\
\text { memiliki } 5 \text { komponen yang dinilai yaitu materi perkuliahan, forum diskusi } \\
\text { LMS, cara belajar mahasiswa, cara dosen mengajar, dan penilaian dalam } \\
\text { bentuk tugas. Hasil penelitian menunjukkan bahwa 96\% mahasiswa } \\
\text { menyatakan senang, 78\% mahasiswa menyatakan baru, } 89 \% \text { mahasiswa } \\
\text { menyatakan antusias, dan 91\% mahasiswa menyatakan tertarik terhadap } \\
\text { perkuliahan berbasis kearifan lokal. Dengan demikian, mahasiswa menyatakan } \\
\text { respon positif terhadap perkuliahan berbasis kearifan lokal pada tiap komponen } \\
\text { penilaian. }\end{array}$} \\
\hline $\begin{array}{l}\text { Kata kunci } \\
\text { respon; kearifan lokal; } \\
\text { Fisika }\end{array}$ & \\
\hline
\end{tabular}


Sitasi: Hikmawati, H., \& Suastra, I.W. (2021), Respon Mahasiswa Terhadap Perkuliahan Berbasis Kearifan lokal Pada Mata Kuliah Kajian Fisika Sekolah Menengah, Kappa Journal. 5(2), 191-199.

\section{PENDAHULUAN}

Kajian Fisika Sekolah Menengah merupakan salah satu Mata kuliah Keahlian Berkarya yang diperuntukkan bagi mahasiswa semester 5 pada Program Studi Pendidikan Fisika, Universitas Mataram. Mata kuliah ini membekali mahasiswa agar dapat memiliki kompetensi dalam mengkaji materi fisika di SMA sebagai salah satu bekal menjadi calon guru yang profesional. Mata kuliah ini menuntut mahasiswa dapat memiliki kreativitas dalam melakukan kajian materi fisika.

Kreativitas merupakan salah satu kemampuan yang harus dimiliki mahasiswa agar dapat bersaing secara global pada abad 21 (Cahyani et al., 2020). Indikator kreativitas diantaranya adalah: Mencari banyak sumber pengetahuan; Memperhatikan penjelasan dari guru; Mampu mencari hubungan-hubungan baru dari sesuatu yang sudah ada; Mampu membuat dugaan; Mampu mengembangkan; Memberikan gagasan yang baik; Mencari banyak kemungkinan; Mempertahankan pendapat; Memberi/menerima saran ataupun kritik; Tidak takut dengan kegagalan. Selain kreativitas, mahasiswa juga diharapkan memiliki keterampilan berpikir kritis, komunikasi, dan kolaborasi (Sari et al., 2015). Keterampilan berpikir kritis mahasiswa sebagai bagian dari kompetensi abad 21 dapat dikembangkan melalui kegiatan analisis artikel ilmiah (Hikmawati Hikmawati, Sahidu, \& Ayub, 2021), pembelajaran berbasis STEM (Hikmawati Hikmawati, Sahidu, et al., 2020), pembelajaran inkuiri (Yuliana et al., 2020).

Selain sejumlah kompetensi tersebut, mahasiswa juga harus memiliki nilai-nilai karakter yang baik seperti sikap peduli terhadap budaya lokal. Sikap peduli terhadap budaya lokal dapat dikembangkan melalui pembelajaran berbasis kearifan lokal (Hikmawati Hikmawati, Suastra, et al., 2020). Kearifan lokal tersebut dapat berupa etnosains, adat istidat, kebiasaan, maupun budaya lokal masyarakat yang dilakukan dalam kehidupan sehari-hari, dilihat di sekitar lingkungan tempat tinggal, dan dialami sendiri oleh mahasiswa (Suastra et al., 2017).

Perkembangan ilmu pengetahuan dan teknologi telah banyak membawa perubahan dalam tiap segi kehidupan. Hal ini memberikan dampak positif dan dampak negatif bagi masyarakat, termasuk mahasiswa sebagai generasi penerus bangsa. Dampak negatif tersebut pada bidang pendidikan diantaranya adalah masih banyaknya perkelahian antar pelajar, kasus bullying di sekolah, narkoba, plagiarisme, kecurangan siswa dalam melaksanakan ujian, dan gejolak masyarakat. Berbagai upaya dilakukan untuk menghadapi tantangan global tersebut, diantaranya adalah perubahan Kurikulum dalam bidang Pendidikan. Kurikulum tidak terlepas dari perencanaan, pelaksanaan, dan evaluasi pembelajaran. Guru yang profesional harus dapat merancang model pembelajaran, metode pembelajaran, dan media pembelajaran inovatif, serta instrumen penilaian yang autentik agar tujuan pembelajaran yang diharapkan dapat tercapai (Kemendikbud, 2013).

Kurikulum pendidikan di Indonesia telah mengalami beberapa kali perubahan. Pembuat kebijakan di Indonesia seharusnya mendesain kurikulum agar generasi muda tidak melupakan kearifan lokal sehingga jati diri bangsa tetap terjaga. Dengan kata lain, pembelajaran di sekolah harus mengintegrasikan pembelajaran berbasis budaya dan etnosains (Suprapto et al., 2021).

Peningkatan kualitas pembelajaran dapat dilakukan melalui pembelajaran yang mengintegrasikan etnosains sebagai bagian dari kearifan lokal (Puspita Hadi et al., 2020). Persiapan yang matang perlu dilakukan oleh guru agar siswa tertarik untuk belajar (Aini et al., 2018). Pendekatan pembelajaran yang dipilih oleh guru perlu memperhatikan berbagai unsur seperti suasana yang nyaman dan menyenangkan, lingkungan yang kaya akan 
pengalaman, dan keterlibatan aktif siswa dalam proses pembelajaran (Kusumawardani, 2015). Aktivitas dan kreativitas siswa dalam proses pembelajaran dapat difasilitasi melalui model pembelajaran yang berbasis kolaboratif (Roshandi \& Koestiani, 2013), seperti pembelajaran berbasis kearifan lokal.

Tujuan penelitian ini adalah untuk mendeskripsikan respon mahasiswa terhadap perkuliahan berbasis kearifan lokal pada mata kuliah Kajian Fisika Sekolah Menengah. Perkuliahan berbasis kearifan lokal ini diharapkan dapat meningkatkan kreativitas dalam melakukan kajian materi fisika, dan kecintaan mahasiswa terhadap budaya lokal, serta nilainilai karakter kebangsaan lainnya.

\section{METODE}

Jenis penelitian yang digunakan adalah penelitian deskriptif karena memberikan uraian tentang respon mahasiswa terhadap perkuliahan berbasis kearifan lokal. Objek penelitian ini adalah respon mahasiswa terhadap perkuliahan pada mata kuliah Kajian Fisika Sekolah Menengah. Responden berasal dari mahasiswa semester 5 yang mengikuti perkuliahan Kajian Fisika Sekolah Menengah di Program Studi Pendidikan Fisika, Universitas Mataram, sebanyak 27 orang. Perkuliahan berbasis kearifan lokal dimulai dari tanggal 18 Agustus 2021 sampai dengan 27 Oktober 2021 dengan jumlah pertemuan sebanyak 10 kali. Perkuliahan tersebut dilakukan secara online melalui Learning Management System (LMS), yang dapat diakses melalui laman https://daring.unram.ac.id//eh responden. Pembelajaran daring ini dilakukan karena adanya pandemi COVID-19. Respon siswa terhadap pembelajaran daring seperti ini termasuk dalam kategori baik (Purniawan \& Sumarni, 2020). Kendala yang terjadi dalam pembelajaran daring selama pandemi COVID-19 adalah banyak menghabiskan kuota serta jaringan internet lemah (Jariyah \& Tyastirin, 2020).

Materi yang dibahas dalam perkuliahan Kajian Fisika Sekolah Menengah adalah: Hakekat Fisika dan Pembelajarannya; Membuat peta konsep; mengkaji materi fisika yang terdiri atas Pengukuran, Gerak lurus, Gerak parabola, Gerak melingkar, Hukum Newton, Usaha (kerja) dan energi, Momentum dan Impuls, Getaran Harmonis, Keseimbangan dan dinamika rotasi, Elastisitas dan Hukum Hooke, Fluida static, Fluida Dinamik, Suhu, Kalor dan Perpindahan Kalor, Teori Kinetik Gas, Hukum Termodinamika, Ciri-ciri gelombang mekanik, Gelombang berjalan dan gelombang Stasioner, Gelombang Bunyi, Alat-alat optic, Rangkaian arus searah, Listrik Statis, Medan Magnet, Induksi Elektromagnetik, Rangkaian Arus Bolak- Balik, Radiasi Elektromagnetik, Teori Relativitas Khusus,Fenomena kuantum; analisis buku siswa SMA kelas X, XI, XII, baik yang buku elektronik maupun buku teks.

Instrumen penelitian ini berbentuk angket respon mahasiswa. Data penelitian diperoleh dengan memberikan angket respon kepada mahasiswa dalam bentuk google form di akhir perkuliahan. Respon mahasiswa dikatakan positif terhadap perkuliahan berbasis kearifan lokal ditinjau dari 4 aspek yaitu senang, baru, antusias, dan tertarik adalah minimal sebesar $75 \%$. Setiap aspek memiliki 5 komponen yang dinilai yaitu materi perkuliahan, forum diskusi LMS, cara belajar mahasiswa, cara dosen mengajar, dan penilaian dalam bentuk tugas (Imelda \& Anazelina, 2019).

Materi perkuliahan yang membahas kearifan lokal diberikan dalam bentuk file Microsoft word, pdf, dan ppt. Forum diskusi pada LMS diatur sedemikian sehingga terjadi diskusi antara anggota mahasiswa dalam satu kelompok, dan diskusi dengan anggota kelompok lainnya. Koordinasi kegiatan diskusi saat perkuliahan juga memanfaatkan platform WhatsApp Messenger Group (WAG). Cara belajar mahasiswa adalah: melakukan wawancara dengan tokoh adat (masyarakat), observasi kearifan lokal yang berupa etnosains, adat istiadat, kebiasaan, budaya lokal masyarakat di Indonesia, terutama suku Sasak di Pulau Lombok; mencari dan melakukan analisis buku referensi dan artikel ilmiah dalam jurnal yang membahas kearifan lokal. Cara dosen mengajar yaitu menjelaskan kearifan lokal melalui 
WAG dan google meet yang berhubungan dengan topik perkuliahan pada mata kuliah Kajian Fisika Sekolah Menengah. Penilaian dalam bentuk tugas individu dilakukan melalui LMS. Soal-soal yang harus diselesaikan oleh mahasiswa dalam tugas tersebut adalah dengan mengintegrasikan topik yang dibahas dengan kearifan lokal yang ada di Indonesia.

\section{HASIL DAN PEMBAHASAN}

\section{Hasil}

Respon mahasiswa terhadap perkuliahan berbasis kearifan lokal pada aspek pertama adalah "senang" sebesar 91\%. Besar persentase untuk tiap komponen penilaian pada aspek pertama ini ditunjukkan oleh Gambar 1.

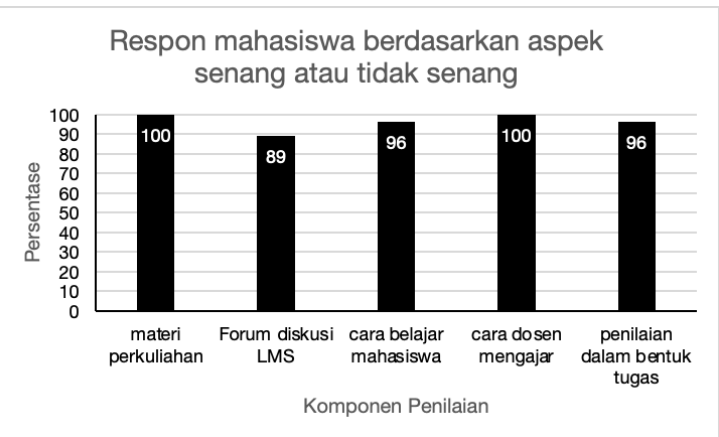

Gambar 1. Respon mahasiswa berdasarkan aspek senang atau tidak senang

Respon mahasiswa terhadap perkuliahan berbasis kearifan lokal pada aspek kedua adalah "baru" sebesar 78\%. Besar persentase untuk tiap komponen penilaian pada aspek kedua ini ditunjukkan oleh Gambar 2.

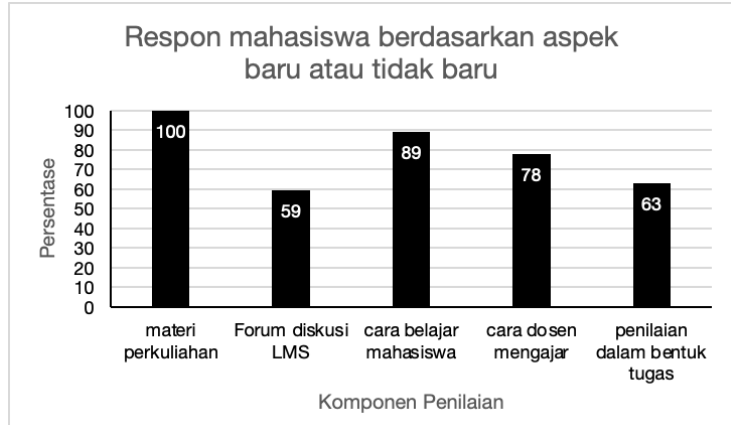

Gambar 2. Respon mahasiswa berdasarkan aspek baru atau tidak baru

Respon mahasiswa terhadap perkuliahan berbasis kearifan lokal pada aspek ketiga adalah "antusias" sebesar 89\%. Besar persentase untuk tiap komponen penilaian pada aspek ketiga ini ditunjukkan oleh Gambar 3.

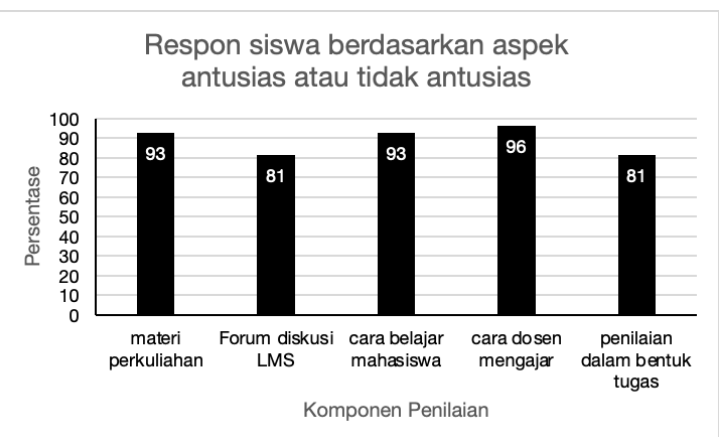

Gambar 3. Respon siswa berdasarkan aspek antusias atau tidak antusias

Respon mahasiswa terhadap perkuliahan berbasis kearifan lokal pada aspek keempat adalah "tertarik" sebesar 91\%. Besar persentase untuk tiap komponen penilaian pada aspek keempat ini ditunjukkan oleh Gambar 4. 


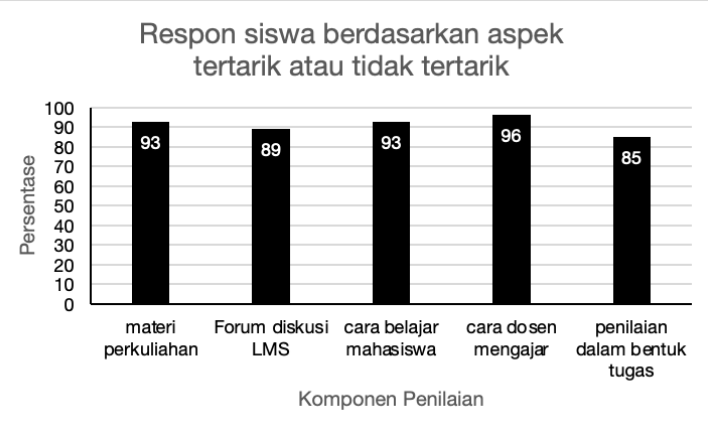

Gambar 4. Respon siswa berdasarkan aspek tertarik atau tidak tertarik

Berbagai alasan 27 orang responden (mahasiswa) menyatakan "senang, baru, antusias, dan tertarik" terhadap perkuliahan berbasis kearifan lokal adalah sebagai berikut. Materi perkuliahan yang diberikan sangat mendukung kegiatan pembelajaran, mahasiswa merasa senang karena tidak merasa kesulitan selama kegiatan pembelajaran, cara dosen mengajar juga luwes dan menarik karena mengaitkan konsep fisika dengan kearifan lokal atau budaya lokal di daerah sendiri maupun budaya dari daerah-daerah lain. Cara belajar mahasiswa melalui kegiatan mengkaji artikel kearifan lokal dan diskusi melalui forum diskusi di LMS dapat meningkatkan kemampuan berpikir kritis. Perkuliahan berbasis kearifan lokal ini merujuk pada lingkungan sekitar, sehingga saat belajar materi fisika juga tidak membosankan. Mahasiswa menyatakan bahwa dari jenjang pendidikan PAUD hingga SMA hanya di Perguruan Tinggi mereka mendapatkan pembelajaran ini, oleh karena itu perkuliahan dengan integrasi kearifan lokal seperti mempelajari hal baru lagi. Upaya penggalian kearifan lokal pada dasarnya untuk mencari, dan akhirnya untuk menetapkan identitas bangsa. Kearifan lokal mengandung nilai-nilai luhur yang perlu dilestarikan. Nilainilai luhur inilah yang menjadi suatu tolak ukur kebaikan yang berkenaan dengan hal-hal yang bersifat mendasar dan abadi dalam hidup manusia. Mahasiswa tertarik karena perkuliahan berbasis kearifan lokal ini tidak monoton dengan rumus dan teori seperti mata pelajaran fisika pada umumnya sehingga perkuliahan sangat menarik dan seru.

Berbagai alasan 27 orang responden (mahasiswa) menyatakan "tidak senang, tidak baru, tidak antusias, dan tidak tertarik" terhadap perkuliahan berbasis kearifan lokal adalah sebagai berikut. Kurang menarik dan agak sulit karena merasa materi ini baru dimata kuliah, mahasiswa masih sulit untuk mengaitkan dengan kearifan lokal. Agak susah mencari hal-hal yang terkait dengan kearifan lokal dengan fisika. Untuk materi terkadang sulit dipahami namun ketika diskusi bertukar pendapat lebih mudah dipahami. Untuk forum diskusi, karena keterbatasan materi yang dikaji, jadi mahasiswa kurang berminat apabila materi yang dikaji di forum diskusi terdiri dari 3 materi karena biasanya jawaban yang diberikan seragam. Ada mahasiswa menyatakan tidak tertarik ke materi dengan alasan terlalu banyak dan untuk materi inti lebih sedikit jadi agak bingung.

\section{Pembahasan}

Keterampilan seseorang untuk mampu bertahan dan mampu bersaing di dunia internasional adalah berpikir kritis dan pemecahan masalah, kreativitas dan inovasi, komunikasi dan kolaborasi (Triana et al., 2020). Keterampilan ini dapat dilatih melalui pembelajaran fisika dan penelitian dalam bidang fisika (Hidayatullah et al., 2021), termasuk mata kuliah Kajian Fisika Sekolah Menengah. Model pembelajaran berbasis 4C (critical thinking, creativity, communication, collabarotion) memiliki pengaruh positif terhadap hasil belajar pada ranah kognitif, psikomotorik, dan afektif (Supena et al., 2021). Pembelajaran yang dapat memfasilitasi perkembangan keterampilan 4C tersebut adalah pembelajaran berbasis kearifan lokal (H Hikmawati, Gunawan, Sahidu, et al., 2021). Budaya lingkungan sekitar memiliki pengaruh terhadap perkembangan keterampilan berpikir, kreativitas, komunikasi, dan kolaborasi (Khoiri et al., 2021). Oleh karena itu, Kebijakan pemerintah 
mengenai sistem pendidikan yang mengintegrasikan keterampilan abad 21 sangat diperlukan (Ağaoğlu \& Demir, 2020).

Materi perkuliahan yang diberikan oleh dosen membantu mahasiswa dalam mengolah informasi untuk menemukan konsep dan membangun konsep secara mandiri. Materi perkuliahan tersebut mengandung unsur kearifan lokal yang dapat berupa etnosains, adat istiadat, kebiasaan, dan budaya lokal masyarakat di sekitar tempat tinggal mahasiswa. Pemanfaatan lingkungan sekitar tempat tinggal siswa terbukti dapat memberikan motivasi belajar dan pembelajaran bermakna (Fua et al., 2018). Materi pembelajaran yang diintegrasikan dengan local wisdom dapat meningkatkan kemampuan kognitif, psikomotor, dan afektif siswa (Kurniawati et al., 2017).

Forum diskusi pada pembelajaran online seperti LMS dapat meningkatkan keterampilan berpikir kritis siswa (Jalinus et al., 2021), dan kualitas pembelajaran yang baik (Hikmawati Hikmawati, Sahidu, \& Kosim, 2021). Forum diskusi LMS pada penelitian ini melibatkan aktivitas mahasiswa dalam memberikan tanggapan dan memberikan penjelasan terhadap tugas yang diberikan oleh dosen. Diskusi terjadi antara mahasiswa dalam kelompok yang sama, serta antara mahasiswa pada kelompok yang berbeda.

Pada perkuliahan berbasis kearifan lokal ini, mahasiswa diminta untuk memberikan hasil analisis atau kajian terhadap topik yang sedang dibahas dengan kearifan lokal yang ada di Indonesia, terutama di Pulau Lombok. Tanggapan dapat dibuat berdasarkan hasil wawancara dengan tokoh adat/tokoh masyarakat, observasi langsung, literatur buku teks dan artikel ilmiah dalam jurnal. Metode kaji literatur dalam bentuk buku teks maupun artikel ilmiah terbukti meningkatkan literasi sains dan literasi budaya mahasiswa (Hikmawati Hikmawati, 2021).

Pembelajaran berbasis budaya lokal sebagai bagian dari kearifan lokal ini dapat meningkatkan keterampilan berpikir kritis dan komunikasi mahasiswa (H Hikmawati, Gunawan, Sahidu, et al., 2021). Pembelajaran berbasis etnosains sebagai bagian dari kearifan lokal dapat meningkatkan sikap peduli budaya siswa (Hikmawati Hikmawati, Suastra, et al., 2020). Disamping itu, pembelajaran berbasis local wisdom juga dapat meningkatkan literasi sains siswa (Setiawan et al., 2017), literasi lingkungan (Ilhami et al., 2019), sikap ilmiah dan keterampilan proses sains (Dwianto et al., 2017).

Beberapa konsep sains yang teridentifikasi memiliki potensi etnosains diantaranya adalah pengukuran, klasifikasi makhluk hidup, zat tunggal dan campuran, getaran dan gelombang, dan bioteknologi (Hikmawati, Suastra, \& Pujani, 2021). Tingkat penguasaan konsep sains yang berbasis etnosains sebagai bagian dari kearifan lokal tersebut dapat diukur melalui asesmen berbasis etnosains. Asesmen yang dikembangkan tidak hanya terbatas pada level Low Order Thinking Skills (LOTS) saja tetapi juga pada level Higher Order Thinking Skills atau disingkat HOTS (H Hikmawati, Suastra, \& ..., 2021).

\section{KESIMPULAN}

Perkuliahan berbasis kearifan lokal pada mata kuliah Kajian Fisika Sekolah Menengah mendapat respon positif dari mahasiswa. Mahasiswa menyatakan senang, baru, antusias, dan tertarik terhadap komponen-komponen perkuliahan yaitu materi perkuliahan, forum diskusi LMS, cara belajar mahasiswa, cara dosen mengajar, dan penilaian dalam bentuk tugas.

\section{SARAN}

Perkuliahan berbasis kearifan lokal dapat digunakan pada perkuliahan lain sebagai upaya untuk meningkatkan ketertarikan dan antusiasme mahasiswa dalam belajar sehingga menumbuhkan kreativitas mahasiswa. Perkuliahan berbasis kearifan lokal juga dapat digunakan sebagai upaya dalam meningkatkan kecintaan mahasiswa terhadap budaya lokal dan nilai-nilai karakter. 


\section{DAFTAR PUSTAKA}

Ağaoğlu, O., \& Demir, M. (2020). The integration of 21 st century skills into education: an evaluation based on an activity example. Journal of Gifted Education and Creativity, 7(3), 105-114.

Aini, Q., Lesmono, A. D., \& Wahyuni, S. (2018). Hasil Belajar, Minat Dan Kreativitas Siswa Sma Pada Pembelajaran Fisika Menggunakan Model Project Based Learning Dengan Memanfaatkan Bahan Bekas. Jurnal Pembelajaran Fisika, 7(1), 1. https://doi.org/10.19184/jpf.v7i1.7218

Cahyani, A. E. M., Mayasari, T., \& Sasono, M. (2020). Efektivitas E-Modul Project Based Learning Berintegrasi STEM Terhadap Kreativitas Siswa SMK. Jurnal Ilmiah Pendidikan Fisika, 4(1), 15. https://doi.org/10.20527/jipf.v4i1.1774

Dwianto, A., Wilujeng, I., Prasetyo, Z. K., \& Suryadarma, I. G. P. (2017). The Development of Science Domain based Learning tool which is Integrated with Local Wisdom to Improve Science Process Skill and Scientific Attitude. Jurnal Pendidikan IPA Indonesia, 6(1), 23-31. https://doi.org/10.15294/jpii.v6i1.7205

Fua, J., Wekke, I., Sabara, Z., \& Nurlila, R. (2018). Development of Environmental Care Attitude of Students through Religion Education Approach in Indonesia Development of Environmental Care Attitude of Students through Religion Education Approach in Indonesia. IOP Conf. Series: Earth and Environmental Science 175Conf. Series: Earth and Environmental Science, 1-8.

Hidayatullah, Z., Wilujeng, I., Nurhasanah, N., Gusemanto, T. G., \& Makhrus, M. (2021). Synthesis of the 21st Century Skills (4C) Based Physics Education Research In Indonesia. JIPF (Jurnal Ilmu Pendidikan Fisika), $6(1), \quad 88$. https://doi.org/10.26737/jipf.v6i1.1889

Hikmawati, H, Gunawan, G., Sahidu, H., \& Kosim, K. (2021). Effect of Local Culture Based Learning in Science on Critical Thinking and Student Communication Skills. Journal of Science and Science Education, 2(1), 8-16. https://doi.org/10.29303/jossed.v2i1.713

Hikmawati, H, Suastra, I. W., \& ... (2021). Assessment in Science Learning Based on Ethnoscience. Jurnal Penelitian ..., 7(3). https://doi.org/10.29303/jppipa.v7i3.736

Hikmawati, Hikmawati. (2021). Kegiatan Analisis Artikel Tentang Etnosains Dan Kearifan Lokal Masyarakat Suku Sasak Untuk Mengembangkan Literasi Sains Dan Literasi Budaya Mahasiswa. 4(3).

Hikmawati, Hikmawati, Sahidu, C., Kosim, K., Sutrio, S., \& Gunawan, G. (2020). Tahap Define dalam Pengembangan Perangkat Pembelajaran Berbasis STEM untuk Meningkatkan Keterampilan Berpikir Tingkat Tinggi Mahasiswa. Kappa Journalpa Journal, 4(2), 149-157. http://e-journal.hamzanwadi.ac.id/index.php/kpj/index

Hikmawati, Hikmawati, Sahidu, H., \& Ayub, S. (2021). Metode Think-Pair-Share Dengan Analisis Artikel Untuk Meningkatkan Keterampilan Berpikir Tingkat Tinggi Mahasiswa. Kappa Journal, 5(1), 20-30. https://doi.org/10.29408/kpj.v5i1.3328

Hikmawati, Hikmawati, Sahidu, H., \& Kosim, K. (2021). Metode Diskusi Berbasis Learning 
Management System (LMS) Untuk Meningkatkan Kemampuan Berpikir Kritis Mahasiswa. 7(1).

Hikmawati, Hikmawati, Suastra, I. W., \& Pujani, N. M. (2020). Ethnoscience-Based Science Learning Model to Develop Critical Thinking Ability and Local Cultural Concern for Junior High School Students in Lombok. Jurnal Penelitian Pendidikan IPA, 7(1), 6066. https://doi.org/10.29303/jppipa.v7i1.530

Hikmawati, Suastra, I. W., \& Pujani, N. M. (2021). Local wisdom in Lombok island with the potential of ethnoscience for the development of learning models in junior high school. Journal of Physics: Conference Series, 1816(1). https://doi.org/10.1088/1742$6596 / 1816 / 1 / 012105$

Ilhami, A., Riandi, R., \& Sriyati, S. (2019). Implementation of science learning with local wisdom approach toward environmental literacy. Journal of Physics: Conference Series, 1-6. https://doi.org/10.1088/1742-6596/1157/2/022030

Imelda, \& Anazelina, D. (2019). Respon siswa terhadap pembelajaran problem based learning dalam meningkatkan Higher Order Thinking Skill. Jurnal of Mathematics Education and Science, 5(1), 11-19.

Jalinus, N., Verawardina, U., Azis Nabawi, R., \& Darma, Y. (2021). Developing Blended Learning Model in Vocational Education Based On 21st Century Integrated Learning and Industrial Revolution 4.0. Turkish Journal of Computer and Mathematics Education, 12(8), 1239-1254.

Jariyah, A., \& Tyastirin, E. (2020). Proses dan Kendala Pembelajaran Biologi di Masa Pandemi Covid-19: Analisis Respon Mahasiswa. The Biology Learning Processes and Constraints in the Covid-19 Pandemic Period: Analysis of Student Responses. Jurnal Penelitian Dan Pengkajian Ilmu Pendidikan: E-Saintika, 4(2), 183-196.

Kemendikbud. (2013). Materi Pelatihan Guru: Implementasi Kurikulum 2013 - SMP/MTs Ilmu Pengetahuan Alam. Badan Pengembangan Sumber Daya Manusia Pendidikan dan Kebudayaan dan Penjaminan Mutu Pendidikan Kementerian Pendidikan dan Kebudayaan.

Khoiri, A., Evalina, Komariah, N., Utami, R. T., Paramarta, V., Siswandi, Janudin, \& Sunarsi, D. (2021). 4Cs Analysis of 21st Century Skills-Based School Areas. Journal of Physics: Conference Series, 1764(1). https://doi.org/10.1088/1742-6596/1764/1/012142

Kurniawati, A. A., Wahyuni, S., \& Putra, P. D. A. (2017). Utilizing of Comic and Jember' s Local Wisdom as Integrated Science Learning Materials. International Journal of Social Science and Humanity, 7(1), 47-50. https://doi.org/10.18178/ijssh.2017.7.1.793

Kusumawardani, R. (2015). Peningkatan kreativitas melalui pendekatan brain based learning. $\begin{array}{llll}\text { Jurnal Pendidikan Usia } & \text { Dini, } & 9(1), & 143-162 .\end{array}$ http://journal.unj.ac.id/unj/index.php/jpud/article/view/3498

Purniawan, \& Sumarni, W. (2020). Analisis Respon Siswa Pada Pembelajaran Daring di Masa Pandemi Covid 19. Seminar Nasional Pascasarjana UNNES, 784-789.

Puspita Hadi, W., Hidayati, Y., \& Rosidi, I. (2020). Respon Guru Ipa Terhadap Pembelajaran 
Ipa Berintegrasi Etnosains: Studi Pendahuluan Di Kabupaten Bangkalan. LENSA (Lentera Sains): Jurnal Pendidikan IPA, 10(1), 46-53. https://doi.org/10.24929/lensa.v10i1.92

Roshandi, W., \& Koestiani, S. (2013). Meningkatkan Aktivitas Dan Kreatifitas Siswa Melalui Collaborative Learning. SMAN 6 Kediri, 148, 148-162.

Sari, D. N., Sutikno, \& Masturi. (2015). Pengaruh Pembelajaran Berbasis Proyek terhadap Kreativitas Siswa melalui Elektroskop Sederhana. Prosiding Seminar Nasional Fisika (E-Journal) SNF2015, 4, 19-24.

Setiawan, B., Innatesari, D. K., \& Sabtiawan, W. B. (2017). The Development Of Local Wisdom-Based Natural Science Module To Improve Science Literation Of Students. Jurnal Pendidikan IPA Indonesia, 6(1), 49-54. https://doi.org/10.15294/jpii.v6i1.9595

Suastra, I. W., Jatmiko, B., Ristiati, N. P., \& Yasmini, L. P. B. (2017). Developing characters based on local wisdom of bali in teaching physics in senior high school. Jurnal Pendidikan IPA Indonesia, 6(2), 306-312. https://doi.org/10.15294/jpii.v6i2.10681

Supena, I., Darmuki, A., \& Hariyadi, A. (2021). The influence of 4C (constructive, critical, creativity, collaborative) learning model on students' learning outcomes. International Journal of Instruction, 14(3), 873-892. https://doi.org/10.29333/iji.2021.14351a

Suprapto, N., Prahani, B. K., \& Cheng, T. H. (2021). Indonesian Curriculum Reform in Policy and Local Wisdom: Perspectives from Science Education. Jurnal Pendidikan IPA Indonesia, 10(1), 69-80. https://doi.org/10.15294/jpii.v10i1.28438

Triana, D., Anggraito, Y. U., \& Ridlo, S. (2020). Effectiveness of Environmental Change Learning Tools Based on STEM-PjBL Towards 4C Skills of Students. Jise, 9(2), 181187. http://journal.unnes.ac.id/sju/index.php/jise

Yuliana, Y., Hikmawati, H., \& Wahyudi, W. (2020). Pengaruh Model Pembelajaran Inkuiri Terbimbing Berbantuan Peta Konsep Terhadap Kemampuan Berpikir Kritis Peserta Didik. Kappa Journal, 4(1), 85-92. https://doi.org/10.29408/kpj.v4i1.1990 